Jovens Químicos não eram alemães. A EYCN colaborou neste encontro, organizando uma sessão satélite sob a temática "Science meets Business", onde se abordaram questões de empregabilidade e mobilidade dos Jovens Químicos (http://www. jcf-fruehjahrssymposium.de/2009/program.htm).

- Austrian Chemical Days é uma reunião bianual da Sociedade Química Austríaca, GOECH, que irá decorrer de 24 a 27 de Agosto de 2009 em Viena. Este evento tem a organização conjunta das sociedades de química austríaca, checa e eslovaca, e incidirá na temática "Chemistry for the world of tomorrow". Inserido neste evento, vai decorrer uma sessão sob o tema "Chemistry after university" organizada pelo grupo de químicos jovens da GOECH. Esta sessão conta com uma conferência plenária do Prof. Dr. Richard Ernst (Prémio Nobel da Química em 1991). Químicos Jovens de todas as nacionalidades são encorajados a participar (www.chemietage.at).
- EuCheMS, $3^{\text {rd }}$ Chemistry Congress vai decorrer em Nuremberga, em 2010, sendo uma organização da Sociedade de Química Alemã. A participação da EYCN, incluindo eventos para Jovens Químicos no programa da EuCheMS, está ainda a ser discutida. No entanto, a EYCN em conjunto com a Sociedade de Química Italiana vai promover a entrega do "III European Young Chemist Award EYCN", como é já tradição nos congressos da EuCheMS. Será que é na terceira edição que ganha um Português? Não se esqueçam de concorrer.

Eleição da Direcção da EYCN e próximos passos: Nesta reunião de delegados da EYCN foi eleita a nova direcção para um mandato de dois anos. As responsabilidades dos seus membros foram redefinidas para ir ao encontro das linhas estratégicas discutidas. O novo presidente é Sergej Toews (Alemanha), assistido por llya Vorotyntsev (Russia, Website), Dan Dumitrescu (Roménia, Comunicações), Helena Laavi (Finlândia, Secre- tária Geral), e Viviana Fluxa (Suíça, ligações com indústria). $\mathrm{O}$ presidente anterior, Csaba Janáky (Hungria), continuará a apoiar a nova direcção como Conselheiro.

Decidiu-se que neste próximo mandato a Direcção da EYCN iria dar particular atenção (i) à renovação do Website como comunicação privilegiada com os Jovens Químicos; (ii) alargar a base de contactos preferenciais com Indústrias de Química Europeia; (iii) continuar a tentar formar uma opinião estruturada participando, quando possível, em órgãos de consulta sobre o futuro da educação da química na Europa; e, (iv) promover a divulgação da química junto da sociedade. Aqui fica o nosso apoio e desejos de um bom trabalho à nova direcção.

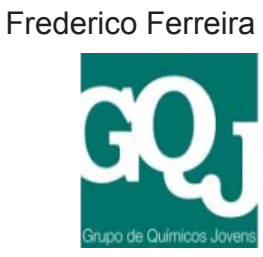

\title{
Relatórios Mostram que a UE está no Caminho Certo, mas o Investimento em I\&D Estagna
}

Os resultados de dois relatórios " $E u$ ropean Innovation Scoreboard 2008" e "Science, Technology and Competitiveness key figures report 2008/2009", recentemente apresentados em Bruxelas pelo vice-presidente da Comissão Europeia Günter Verheugen e pelo Comissário para a Ciência e a Investigação Janez Potocnik, mostram uma melhoria substancial em certas áreas mas mostram também que o investimento em I\&D (investigação e desenvolvimento) na UE27 está a estagnar.

O investimento público e privado em I\&D e em inovação é considerado essencial para ajudar as economias a estabilizarem e sairem deste período de crise. Contudo, a intensidade de investimento em investigação (volume investido em I\&D comparado com o PIB) não aumentou nos últimos anos, permanecendo em cerca de 1,84\%. Segundo o Comissário Potocnik "Em tempo de crise, não é o momento para reduzir os investimentos em investigação e em inovação. Eles são vitais se a Europa quiser sair forte desta crise económica [...] As iniciativas da Comissão para melhorar a eficiência da investigação na UE, estimular a inovação e desenvolver os mercados de tecnologia de ponta, estão a colocar a UE no caminho certo."

O Comissário Verheugen concordou, dizendo, "Uma crise é uma coisa terrível para ser desperdiçada. É importante que nos armemos com todas as possibilidades e façamos uma recomendação muito forte às companhias europeias para não cortarem no investimento, nos gastos em investigação, desenvolvimento e inovação, e para não despedirem os empregados altamente qualificados porque precisamos de todos eles."

Nenhum dos dois relatórios reflecte ainda o impacto da presente crise económica. Contudo, ambos os relatórios mostram que as universidades europeias formam cada vez mais estudantes graduados. Muitos deles podem ser perdidos para regiões competidoras por falta de oportunidades de emprego. $O$ investimento estrangeiro na UE27 aumentou substancialmente, sendo a Europa responsável por $62 \%$ do investimento estrangeiro em I\&D nos EUA.
Todos os Estados Membros da UE aumentaram os seus gastos em I\&D entre 2000 e 2006, mostrando o seu compromisso com a estratégia de Lisboa de investir 3\% do PIB em I\&D. Em particular, Portugal e a Grécia fizeram esforços notáveis. Contudo, muitos continuam a investir abaixo da média. O Comissário Verheugen disse, referindo-se à Itália, Espanha e Lituânia, que "é essencial que se faça um esforço concertado para melhorar a situação."

Em termos de competitividade, Finlândia, Suécia e Suiça tiveram desempenhos excepcionais, mas a intensidade de investimento em I\&D não aumentou no Reino Unido, França ou Itália, e aumentou apenas ligeiramente na Alemanha. Este aspecto é importante porque estes são os países com o maior PIB na UE27.

Enquanto a diferença em investimento entre os Estados Membros Europeus tem vindo a diminuir, a estagnação geral está a ter impacto na competitividade global da Europa, especialmente face ao rápido crescimento da 
China. É de realçar que 12 Estados Membros têm maior intensidade de investimento do que a China enquanto que 15 gastam muito menos do que a China em investigação. O investimento em I\&D no Japão, Coreia do Sul e China tem vindo a aumentar, e enquanto que a intensidade de investimento dos EUA tem vindo a diminuir, esta diminuição ocorre a partir de uma posição muito forte.

De acordo com a Comissão, a UE está ainda longe de atingir o objectivo de Lisboa. "Um continuado baixo nível de investimento em I\&D, ligado a uma estrutura industrial Europeia com um sector de alta tecnologia mais pequeno do que os EUA, limita a performance da UE [...] A UE deve mudar a sua estrutura industrial, promover a inovação e assegurar mais e melhor uso da I\&D."

É necessário criar condições favoráveis a SMEs de alta tecnologia e de rápido crescimento, a par de um mercado Europeu mais aberto à inovação e de melhor acesso a um sistema de patentes alargado a toda a UE.

Em termos de inovação, Dinamarca, Alemanha, Finlândia, Suécia e Reino Unido são lideres, "com uma performance de inovação muito acima da média da UE e de todos os outros países. A Alemanha é a que apresenta uma mais rápida melhoria de performance enquanto que a Dinamarca está a estagnar."
Criatividade e inovação estão intimamente ligados. Os países com bons climas de criatividade tendem a ter níveis mais elevados de I\&D e de actividades de design, e ainda uma performance de inovação global forte.

Um número crescente de investigadores de países terceiros está a ser atraído para a Europa e a Europa está a formar mais graduados de investigação do que nunca; contudo, a fracção de investigadores no mercado de trabalho é ainda inferior à dos EUA ou Japão. Os investigadores Europeus publicam mais do que os de qualquer outra região em jornais profissionais, mas os investigadores dos EUA ainda lideram em termos de publicações de impacto elevado. O relatório da competitividade indica ainda que há necessidade de melhorar o número de patentes Europeias.

Ainda em relação à inovação, "O hiato ainda existente em relação quer aos EUA quer ao Japão está concentrado em quatro áreas: patentes internacionais [...], ligações privado-público e número de investigadores (apesar das melhorias registadas nestas duas áreas) e gastos em I\&D."

O Comissário Potocnik concluiu, dizendo: "Os primeiros passos dados para implementar a Área de Investigação Europeia (European Research Area), aferida pela primeira vez neste relatório, mostram resultados encora- jadores. A UE tornou-se mais aberta ao mundo e é cada vez mais atractiva para investimentos, estudantes e investigadores estrangeiros. Há ainda trabalho a fazer para acelerar estas tendências mas as acções tomadas pela Comissão e pelos Estados Membros estão a começar a mostrar resultados."

O "European Innovation Scoreboard" é uma publicação independente e inclui os indicadores de inovação e análises de tendências dos Estados Membros da UE27 e ainda da Croácia, Turquia, Islândia, Noruega e Suiça.

Para mais informação, consultar:

Science, Technology and Competitiveness key figures report 2008/2009:

http://ec.europa.eu/research/era/ publication_en.cfm

European Innovation Scoreboard 2008:

http://www.proinno-europe.eu/ EIS2008

European Research Area: http://ec.europa.eu/research/era

JM

\section{Curiosidade Científica}

\section{VinHO MEDICINAL UTILIZADO HÁ 5100 ANOS}

A descoberta recente de sais cristalinos provenientes da degradação de ácido tartárico (componete do vinho) juntamente com resinas extraídas de árvores no interior de uma ânfora encontrada na câmara funerária do Rei Escorpião I, em Abydos (Egipto) sugere que o vinho, como prática medicinal, tenha sido introduzido no antigo Egipto há cerca de 5100 anos. A investigação, que fez recuar um capítulo da história da medicina em 1300 anos, fornece pistas para novas terapias aplicadas a doenças actuais, como por exemplo, fármacos anticancerígenos. Os curandeiros ancestrais utilizavam infusões de ervas com propriedades medicinais em vinho, por estas se preservarem melhor e serem mais eficazes do que infusões em água. Existem mesmo vários registos escritos antigos que referem a utilização e descrição de «receitas» de infusões de vinho medicinal, tendo sido os mais antigos encontrados no Egipto, em papiros datados de 1850 A.C. A descoberta, publicada na revista "Proceedings of the National Academy of Sciences" esta semana, por parte de uma equipa de investigadores da Universidade de Pensilvânia
(EUA) liderada por McGovern, indica a presença de vestígios de um conjunto possível de ervas, incluindo segurelha, erva-cidreira, sene, coentros, menta, salva e tomilho, juntamente com vinho e resinas de ávores, num troço de ânfora cujo fabrico se estima ter ocorrido no ano 3150 A.C. Os autores da descoberta, em colaboração com investigadores na área da terapia para doenças cancerígenas, exploram agora as propriedades medicinais de ervas encontradas em vinhos e cervejas antigas como possíveis novos fármacos.

(Adaptado de ScienceNOW Daily News de 14 de Abril) Ana Charas 